\title{
A Catalogue of Nearby Wide Binary and Multiple Stars
}

\author{
A. PovedA, M. A. Herrera, C. Allen, G. CORDERo, \& \\ C. LAVALLEY \\ Instituto de Astronomía, UNAM, Apdo Postal 70-264, \\ 04510 México D.F., México
}

\section{ABSTRACT}

No modern catalogue of wide binary and multiple systems (WBMS) exists for the region of the solar vicinity (stars nearer than $\sim 22 \mathrm{pc}$ ), that include updated information on their membership to moving clusters and an age classification. With the aim of filling this gap, and also because of its importance for investigating the dynamical evolution of double and multiple systems, we have compiled a WBMS list extracted from the catalogues of nearby stars of Gliese $(1969$, also Gliese \& Jahreiss 1979), as well as Luyten's NLTT (Luyten 1979-1980, Luyten \& Hughes 1980, see also Warren et al. 1989), the Bright Star Catalogue (Hoffleit 1982), the catalogue of Woolley et al. (1970) and other sources.

By comparing the transverse velocities of WBM systems with those expected for members of the Hyades and Sirius Superclusters, membership of some WBMS to them has been established. We have classified as probably young systems (PYS) those with one component satisfying at least one of various criteria of youth. A system that is not a PYS is classified as probably old (POS).

The catalogue contains 385 binaries and 85 systems of higher multiplicity. Out of these, 129 binaries are PYS and 256 are POS, while 32 multiples are PYS and 53 are POS.

\section{REFERENCES}

Gliese, W. 1969, Veroff. des Astronomischen Rechen-Instituts, Heidelberg. No. 22 Gliese, W. \& Jahreiss, H. 1979, A\&AS, 38, 423

Hoffleit, D. (with the collaboration of Jaschek, C.) 1982, The Bright Star Catalogue, 4th revised edition (New Haven, Yale Univ. Obs.)

Luyten, W.J. 1979-1980, New Luyten Catalogue of Stars with Proper Motions Larger than Two Tenths of an Arcsecond, (University of Minnesota, Minneapolis), Vols. 1-4

Luyten, W.J. \& Hughes, H.S. 1980, Proper Motion Survey with the Forty-Eight Inch Schmidt Telescope. LV. First Suppplement to the NLTT Catalog, (University of Minnesota, Minneapolis)

Warren, W.H., Jr., Sturch, C.R., Jahreiss, H., Lasker, B.M., \& Luyten, W.J. 1989, AJ, 97,1480

Woolley, R., Epps, E.A., Penston, M.J., \& Pocock, S.B. 1970 Catalogue of Stars within 25 parsec of the Sun, Royal Obs. Annal 5 